\title{
Perceive of Nursing Students about Licentiate Disciplines
}

\section{Ana Carolina Silva Gonçalves ${ }^{1}$, Ana Laura Linhares de Oliveira1, Isabella Cabral dos Santos', Kamila Silva de Miranda1, Liessa Aparecida Vaz', Thayna Martins Gonçalves, Omar Pereira de Almeida Neto ${ }^{2}$}

\author{
${ }^{1}$ Federal University of Uberlandia, Uberlandia, Brazil \\ ${ }^{2}$ Nursing Department, Medicine School, Federal University of Uberlandia, Uberlandia, Brazil \\ Email: omarpneto@hotmail.com
}

How to cite this paper: Gonçalves, A.C.S., de Oliveira, A.L.L., dos Santos, I.C., de Miranda, K.S., Vaz, L.A., Gonçalves, T.M. and Neto, O.P. de A. (2020) Perceive of Nursing Students about Licentiate Disciplines. Open Access Library Journal, 7: e6270.

https://doi.org/10.4236/oalib.1106270

Received: March 25, 2020

Accepted: April 11, 2020

Published: April 14, 2020

Copyright ( $) 2020$ by author(s) and Open Access Library Inc.

This work is licensed under the Creative Commons Attribution International License (CC BY 4.0).

http://creativecommons.org/licenses/by/4.0/

(c) (i) Open Access

\begin{abstract}
Introduction: Undergraduate Nursing Courses have trying to prepare nurses to act as teachers in various teaching scenarios, despite still gaps in the student's understanding. Objectives: To report the experience and evaluate the perceptions of undergraduate nursing students in relation to the disciplines of integrated project of educational practices I (PIPE I) and Interdisciplinary Project I (PROINTER I). Methods: Descriptive and quantitative study. Nursing students were recruited to answer a questionnaire made available via Google Forms ${ }^{\oplus}$, with questions self-made related to the above-mentioned subjects. Results: A total of 17 students composed the study sample, aged between 17 and 30 years. Regarding the importance of the disciplines, 50\% did not recognize (PIPE I) and 71.4\% (PROINTER I). In the students' view, the didactics used by the professor responsible for the discipline of PIPE I was efficient in the transmission of knowledge (60\%), in relation to the objective of the PIPE I discipline, 50\% had knowledge, as well as $71.4 \%$ in PROINTER I. Conclusion: It was observed that most students do not recognize the meaning and importance of the degree for their academic education, as well as the objective and relevance of the disciplines PIPE I and PROINTER I.
\end{abstract}

\section{Subject Areas \\ Education, Nursing \\ Keywords \\ Disciplines, Education, Nursing, Nursing Degree}

\section{Introduction}

Licentiate nursing degree is a course made to meet a collective need for 
mid-level professionals and also with the purpose of developing engaged teachers in social change, innovation, supportive and involved with the community responsibly and always following ethical precepts, so that for this training and performance of this post, it would be essential to BA [1].

The grade curriculum nursing course has proposed to train graduate nurses so they can act as teachers in various teaching scenarios. Such training is not limited to theoretical knowledge and technicians from the health sector, but covers cognitive knowledge, procedural and attitudinal. It is also considered joining disciplines didactic and pedagogical training to better assist in vocational training, such as the Teaching, Psychology, Sociology and Anthropology [2].

The field of education favors the formation of licensed nurses, the importance of this area to the extent that it is expected the construction of an interconnected professional with a specific area of training (Nursing) is noticed, with consistent knowledge of educational issues, educational and those related to the teaching-learning steps [2].

The formation of the pedagogical development is and will be extremely important for the activity and performance of the nurse-teacher, as has the duty to enable and prepare other professionals; you must have knowledge and practices that help in the creation of teaching and learning considerably and important in other levels of education, such as training in technical education [3].

In the path of training for teachers, the nurse who has degree through the traineeship exercised in technical health schools, conducts technical professional future nursing in providing care to patients from different health institutions [4].

Professional competence has been numerous approaches' target and at the same time, due to concerns by health service managers and trainers of professional institutions. For such a situation, the National Curriculum Guidelines (DCN) declare these forming health professional institutions to some professional and academic skills profile, which includes leadership skills, problem solving in decision-making, management, among others. In nursing courses, especially the DCN bring unique skills that integrate theoretical and practical components in the foundation and development of educational project courses that permeate the training of nurses [5].

Thus, the Integrated Project Educational Practices (PIPE) are curriculum integrating components that respond to this demand of DCNs. The PIPEs are met in practice hourly load in the different areas of teaching and learning of nursing as schools, health facilities, kindergartens, hospitals, businesses and clinics. In addition, the Interdisciplinary Projects (POINTER) are curriculum components which aim to articulate the theory and practice throughout the formation of the student and deepen themes aimed at the training of teachers in the different areas contained in the political pedagogical project of the course (PPC). The POINTER seeks to develop the scientific spirit, through research that question the educational context in which the projects will be developed [6]. 
Once explicit the importance of the relationship between BA and degree in Nursing, as the various areas listed actions the pedagogical field of nurses, this research aims to facilitate reflection and criticism about the experiences and perceptions of undergraduate students in nursing a Public University of Minas Gerais in relation to discipline PIPE 1 and POINTER 1. In addition, aims to examine whether students have prior knowledge to enroll in the academic environment from the perspective of what is the degree and understanding of the importance of it, allowing you to compare the perspectives of students entering the nursing program with qualification degree and bachelor's degree in the second half of 2016 and on the prospects of students tickets for the first half of 2019, whose year was implemented the curriculum reform of the undergraduate course in Nursing university in question, in which there was reformulation of the menu offered some disciplines.

\section{Methodology}

Kind of study

Descriptive research with quantitative and qualitative approach.

Location Study

The study was developed in the curricular component PIPE 6, component this makes a technical and pedagogical analysis of PIPEs and POINTER already routed by students enrolled in the undergraduate course in Nursing (Bachelor/Bachelor), Federal University of Uberlandia.

Data collection procedures

The data collection procedure was as follows: Researchers in possession of a spreadsheet provided by the ongoing coordination made online contact with students enrolled in PIPE 1 and POINTER 1. A link to data collection instrument was made available via Google Docs ${ }^{\circledast}$ with questions concerning the analysis of the PIPE 1 discipline and POINTER 1 for students enrolled in the courses. After this, we proceeded to the collaboration of the participant sample, which returned the questionnaires. Researchers performed tabulation and validation of data in Excel spreadsheets by making descriptive statistics for categorical figures.

Data Collection Instrument

A data collection instrument semi-structured self-made based on literature and pedagogical teaching experience of the researchers on the perception of the students who attended the disciplines of PIPE 1 and POINTER with qualitative issues was created: knowledge of disciplines, knowledge about the goals of disciplines, knowledge about the inclusion of subjects in degree, the perception of practical classes of disciplines, knowledge about the schedule and proposed activities for discipline, student activities on the hourly practice burden of disciplines, as well as a quantitative question: how many days of practice activities subjects.

Sample

It was composed by students' Undergraduate course in Nursing (Bache- 
lor/Bachelor), Federal University of Uberlandia, who attended the discipline PIPE 1 in the second half of the year 2016 and students who attended the field of POINTER 1 in the first half of 2019in order to compare their perceptions.

\section{Results}

A total of 17 students composed the study sample, divided as follows: 10 students who attended the discipline of PIPE 1 in the first semester the year 2016 and 7 students who attended the field of POINTER 1 in the first half of 2019.

It is noteworthy that the PIPE 1 and POINTER 1 courses are equivalent in content, and change the name due to PPC change of course in the period when this research was conducted.

The participants were students of the Federal University of Uberlandia Nursing graduation, with age between 17 and 30 years, $80 \%$ of students were female gender, in second year stage of course and almost all answered uncomfortable studying licentiate disciplines.

Based on the results, it was possible to prepare the following tables:

To reflect on the concept of PIPE and I POINTER I, there were differences between the responses, as evidenced by Table 1 . Regarding the purpose of PIPE I discipline, 50\% of students did not know their purpose, on the other hand relative I POINTER to this figure rises to $71.4 \%$.

According to statistics, most students who attended the subject PIPE I (90\%) knew that belonged to the degree such matter. In relation to students who are attending POINTER I discipline, about 57\% reported that they did not know and only about $43 \%$ knew.

On the number of classes designed to dispersions, responses had divergence in about $5 \%$, and the PIPE I class $80 \%$ of respondents believed that the dispersions were sufficient to carry out the proposed activities, while in POINTER I class, this number was $85.7 \%$.

Table 1. Frequency distribution of the responses to student perception questionnaire regarding undergraduate disciplines PIPE 1 and POINTER 1, Uberlandia, 2019.

\begin{tabular}{lllll}
\hline VARIABLE INSTRUMENT & I PIPE & & I POINTER \\
\hline & YES (\%) & NO (\%) & YES (\%) & NO (\%) \\
\hline $\begin{array}{l}\text { Do you know what are the objectives of } \\
\text { this discipline? }\end{array}$ & $50 \%$ & $50 \%$ & $28.60 \%$ & $71.40 \%$ \\
$\begin{array}{l}\text { Did you know that I POINTER/PIPE I } \\
\text { is a matter of degree? }\end{array}$ & $90 \%$ & $10 \%$ & $57.10 \%$ & $42.90 \%$ \\
$\begin{array}{l}\text { In his view, the amount of dispersion } \\
\text { was/will be required to carry out all the } \\
\text { activities proposed on the menu? }\end{array}$ & $80 \%$ & & & \\
$\begin{array}{l}\text { The teaching that is being used by the } \\
\text { teacher was effective in imparting } \\
\text { knowledge? }\end{array}$ & $60 \%$ & $40 \%$ & $85.70 \%$ & $14.30 \%$ \\
\hline
\end{tabular}


In the view of the students interviewed, the teaching used by the teacher responsible for the PIPE I discipline was effective in transmitting knowledge, evidenced by the number of favorable responses in case $60 \%$. Compared to discipline POINTER I, this figure drops to $42.9 \%$ (Figure 1).

Analyzing the amount of the PIPE I dispersions course, the divergence was observed compared to their responses. Over the period they were carried out seven dispersions marked by the teacher so that students could carry out the activities. It is believed that the disagreement in results may be due to the sum of meetings with the teacher to answer questions and also due to forgetfulness of the students, since there is a difference of three years of entry between the compared groups (Figure 2).

In collecting answers regarding POINTER I dispersions, it was found that there is also the presence of divergence. It is considered hypothetically that the lack of interest in the discipline has caused this divergence response.

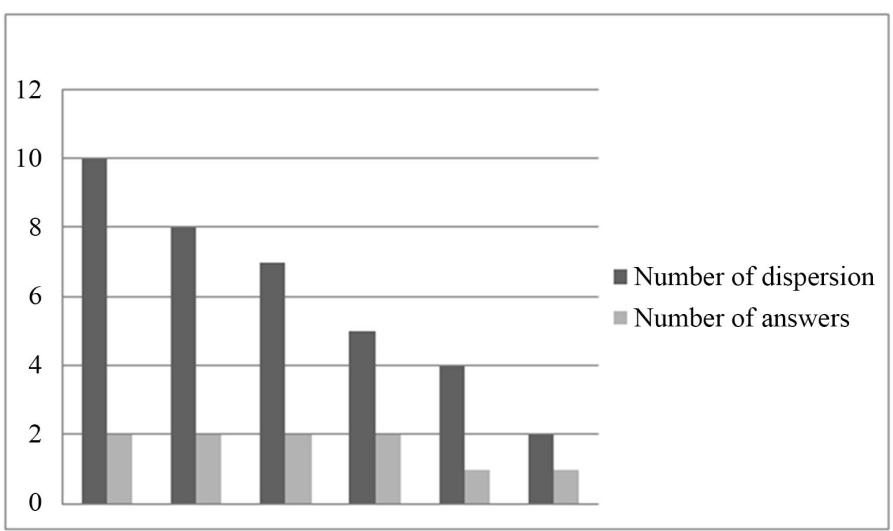

Figure 1. Frequency distribution of the responses to the quantitative questionnaire about the perception of students in the practices of dispersions PIPE 1 degree of discipline, Uberlandia, 2019. Source: the authors.

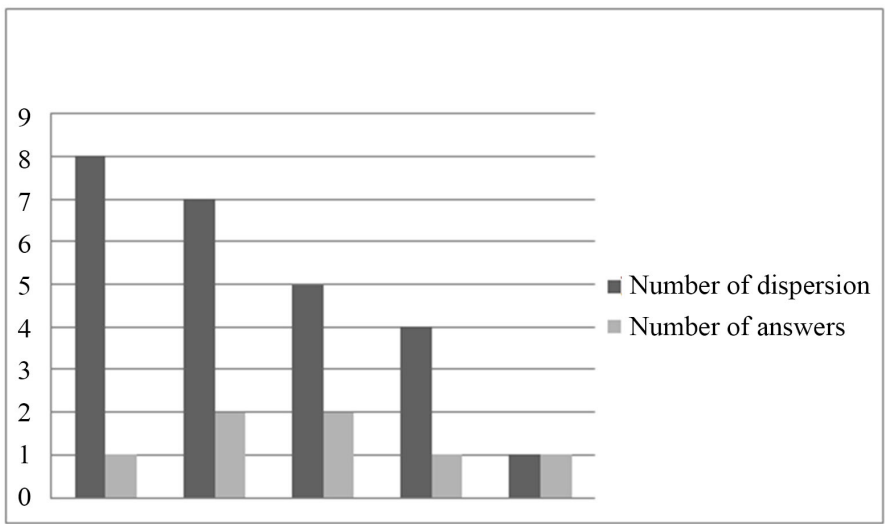

Figure 2. Frequency distribution of the responses to the quantitative questionnaire about the perception of students in the practices of dispersions POINTER degree of discipline 1, Uberlandia, 2019. Source: the authors. 


\section{Discussion}

Consistent with the results of a previously published study, it is noted that the motivational profile of undergraduate students is quite varied. There are strong relationships between the intrinsic motivation of students and the mandatory involvement in academic activities, since some students have some concern about the development of knowledge and studies to optimize their specific assignments, when inserted in the labor market, if, for personal gain [7].

Another feature of these students is quite remarkable involvement in academic activities required to achieve the ideal time to completion of undergraduate degree, confirming the observation of personal gain. The obligation to comply with the predetermined is a decisive factor academic activity on reducing the motivation for the search for new knowledge and deepening of the topics taught in degree, culminating in the total lack of interest in sport [8].

Both the discipline PIPEI, as well as the PROINTERI have on your schedule school days allocated to that dispersions in the university context, are recognized as a time reserved for students to meet pre-established groups with the purpose of performing the proposed activities to be presented to class the following week. The elaborate questionnaire also had the following discursive question "What did you do in the days of the dispersions?" And among the seventeen (17) responses obtained in PIPEI PROINTERI and, respectively, $60 \%$ and $42.85 \%$ carries out work other content, $30 \%$ and $28.57 \%$ consider vague time and only $10 \%$ and $28.57 \%$ held the proposed activity.

Furthermore, although the purpose of this step is explained by the teachers and be described in schedule, according to the number of dispersions presented by the students in the survey means that they were not aware of the discipline lesson plan, as they were obtained 6 (six) different responses, regardless of these results an average of $82.85 \%$ of students who participated in this research answered that the amount of outside dispersions essential to perform all activities proposed in the menu. Therefore, it is possible to identify contradictions by the students before and it is essential that the real need to book school days for the dispersions to be identified in the subject, as if the students do not use this time to its true purpose,

In teacher education programs the teaching has indispensable role, representing the discipline that prepares students for reflective teaching practice, making the important points that should meet the events outside the higher education institutions, impacting so in the Brazilian education system [9].

According to the results analyzed, most of the students said that the teaching of teachers is essential to the transmission of knowledge. The educator is responsible for awakening and captivating the interest of students by subject matter, making the student the main subject of the construction of new knowledge, being an active agent in the formation of knowledge. The didactic used by educators is essential for students to awaken ideas and innovative thinking in students, in addition furthermore the teaching methods used by the teacher to ex- 
pose their knowledge can also influence the formation of the role of educator of the students, who will be future educators.

In this sense, health promotion references give trainings in the field of nursing a transformative re-signification of teaching practices, favoring the overcoming of the hegemonic model of technical rationality that still characterizes the training and the performance of health professionals. From this perspective, the teaching-learning process in nursing requires educational and health care practices that empower the subjects to act in the effective social changes. When applying the active methodologies, such references contribute to critical thinking as well as a participative role in the construction of knowledge, not to mention a contextualized vision of the reality and necessary autonomy to act in decision-making process [10].

According to COFEN, in 2018, the labor market to care and nurse managers in recent years, have imposed greater demands on trained professionals to operate, a fact that has direct action on the formation of the current academic [11]. As an undergraduate in nursing course in bachelor's and degree mode, the required stages of the subjects of the curriculum components are meant for hospital care and occur along the graduation, and the stages of the very limited degree of disciplines, restricted to final periods of University graduate. The lack of degree courses stages and the fact that they are evenly distributed along the graduation, linked to the imposition of nursing care,

As disciplines in the degree modality, the nursing course at the researched university consumed $40 \%$ of the entire curricular component of the first undergraduate period. This number of disciplines, introduced in the academic environment of students who have recently completed high school, is important for a licensing presentation regarding the mandatory form in the training and in the beginning of the study of the contents present in the subjects in question. The didactics and methodologies used by the teacher of classes, the incentive to research, one of the pillars of the entire institution of higher education, encourages students to engage in teaching, the analyzes of professional performance totally different when compared to students who follow the assistance or administrative axis. In addition, this fact is a predictor in the direction of activities carried out within the university and in the construction of the academic.

\section{Final Considerations}

From the analysis of the data it is noted that most students do not recognize the significance and importance of the degree for their education, and also, do not recognize the purpose and relevance of the subjects I PIPE and POINTER I.

Thus, identifying the need to create methods that work with the students of the degree view and the subjects of the curriculum are part of this, to improve the level of understanding of nursing students on the subject. This study provides benefits for nursing areas, due to the fact it is a topic rarely addressed and of great importance to the training of nurses. 
Based on the analysis of data generated by the questionnaires, most graduate nursing students fail to recognize the purpose and importance of the subjects of PIPE I and POINTER I, just do not realize the purpose of degree in their education.

It is clear that especially at the beginning of the course, the degree and the bachelor do not have an integrated way, based on that they need to work out methods with the students in order to stimulate interest and improve the level of understanding about the degree so that everyone understands the need for it in the formation of a nursing professional, because the degree enables both a selection of work where nurses can work in classrooms, and for that nurse makes an effective health education, always seeking that he develops your interpersonal communication skills, which is extremely important in any service level.

However, with the lack of knowledge about the degree and its importance in the academic and professional training, there are great evasion incidences of university nursing students researched, especially in the first period graduation, confirming the setting of the degree in perspectives of students. This study brings beneficial contributions to nursing, to the extent that it is a subject still little explored, but it can be a very good ground for new research that is dealing with a highly relevant topic for the construction and training of nurses.

Some barriers can be found in that article. The number of students that answered the questionnaire could be improved in future researches in order to that theme being more explored. Besides, other questionnaires, methodologies and data statistical analyses show different visions about that theme.

\section{Conflicts of Interest}

The authors declare no conflicts of interest regarding the publication of this paper.

\section{References}

[1] Santos, S.M. dos R., et al. (2011) Degree and Bachelor's Degree in Nursing: Experiences and Expectations of Students. Nursing Journal of Rio Grande do Sul, 32, 711.

[2] Oliveira, W.A., et al. (2018) The Didactic and Pedagogical Training of Licensed Nurses: The Perspective of Teachers. Plures Humanities, 19, 312-325.

[3] Santos, C.M.L., et al. (2014) A Degree in Nursing in Brazil (1968-2001): A Literature Review. Nursing History. Electronic Journal, 5, 224-238.

[4] Vaz, D.R., et al. (2017) Reflection Importance of Curriculum Training in Nursing Degree: Using Heuristic. Journal of Graduate USP, 2, 65-73. https://doi.org/10.11606/issn.2525-376X.v2i2p65-73

[5] Leal, L.A., et al. (2016) Professional Skills for Nurses: the Vision of Graduate Students in Nursing. Nursing Journal of Bahia, 30, 1-12.

[6] University of Federal Uberlândia (2019) Pedagogical Course in Nursing Project. UFU, Uberlandia. http://www.famed.ufu.br/node/81

[7] Porto, R.C and Gonçalves, M.P. (2017) Motivation and Academic Involvement: A Study with University Students. School and Educational Psychology, 21, 515-522. 
[8] Guimaraes, B.E., Bzuneck, J.A. and Sanches, S.F. (2002) Educational Psychology in Graduate Courses: Students' Motivation. Psychology School and Educational, 6, 11-19.

[9] Oliveira, A.T., De C.C. and Fiorentini, D. (2018) The Role and Place of Teaching Specific Initial Training of Mathematics Teachers. Revista Brasileira de Educação, 23, 1-17. https://doi.org/10.1590/s1413-24782018230020

[10] Mendes, A.C., et al. (2018) Educação em enfermagem de saúde mental e psiquiatria no curso de licenciatura em enfermagem. SMAD Revista Eletrônica Saúde Mental Álcool e Drogas, 14, 73-83.

[11] COFEN (2019) Labor Market for Nursing Expands Business Areas. Nursing Federal Council in 2018.

http://www.cofen.gov.br/mercado-de-trabalho-para-enfermagem-amplia-areas-de-a tuacao_65154.html 